\title{
Infrastructure buildings - New design language for urban architecture: Bus stations, tram stations, transfer hubs
}

\author{
Gerd Schmid \\ * formTL ingenieure für tragwerk und leichtbau $\mathrm{GmbH}$ \\ Güttinger Str. 37, 78315 Radolfzell, Germany \\ e-mail: info@form-tl.de, http://www.form-tl.de
}

\begin{abstract}
Traffic jams, increased road repairs and missed transfers do not surprise, when we hear that the number of kilometers traveled has doubled in the past 10 years

Well-coordinated and realistic time tables, and compact transfer points. So bus stops and tram nodes in the immediate neighborhood of train stations and airports with their classic cabstands and parking garages.

Cities and municipalities are increasingly investing in high performance hubs where the means of transport can be changed. Depending on the location, supplemented by e-bikes and scooters or carsharing parking spaces as well as shops for daily needs.

We had the opportunity to work on several special projects in excellent teams as structural engineers for roofs, which simply have to function as functional buildings and, thanks to their architecture, make the location recognizable. Our clients therefore like to speak of functional urban art - of urban identification points with quality of stay for our modern and increasingly mobile society.

Our competition entries for the city train station Ulm (D, 2014), the ZOB Backnang (D, 2017), the "Wölkli" in Aarau (CH, 2013), the bus station in Hamburg Barmbek (D, 2012) and the ongoing planning for the bus station in Altdorf (CH, 2019-23) and the tram station Elifelet in Tel Aviv (20202021) provide answers and make suggestions.

All projects are characterized by a particularly sustainable and integrated construction method that, thanks to the materials used, looks valuable even after years.
\end{abstract}

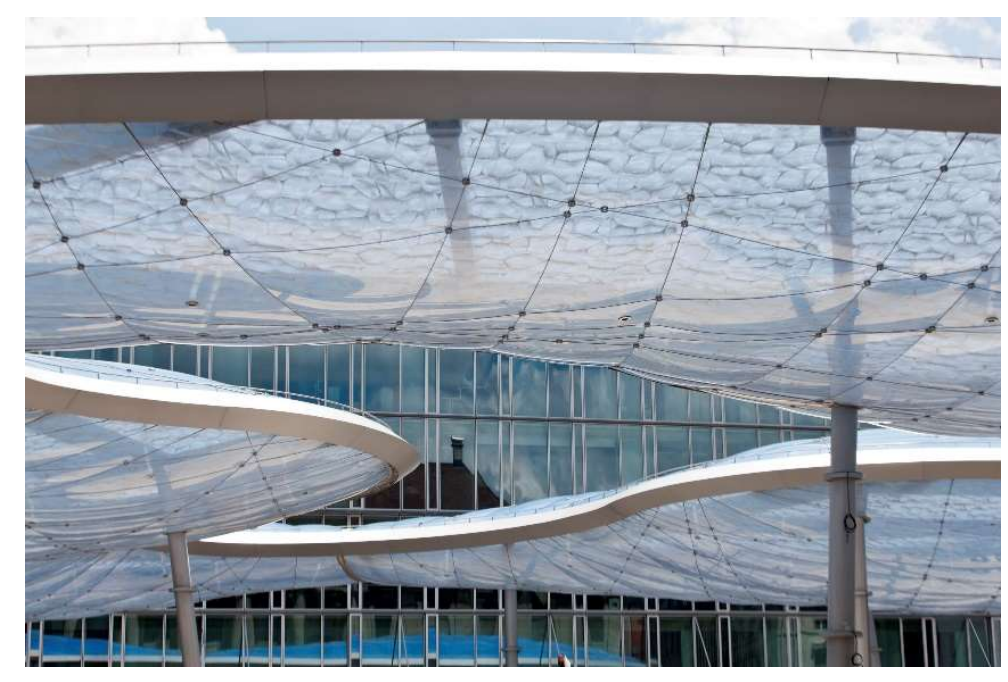

Bus Terminal Aarau / Picture: Niklaus Spoerri 


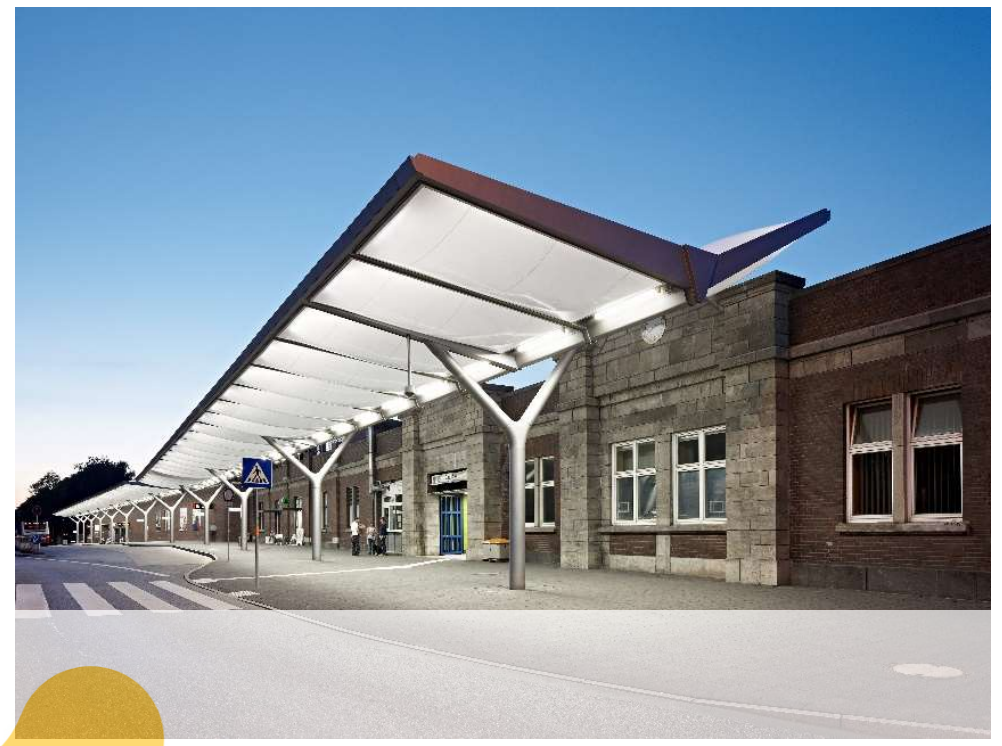

Bus station roof Hamburg-Barmbek / Picture: ARCHIMAGE Meike Hansen

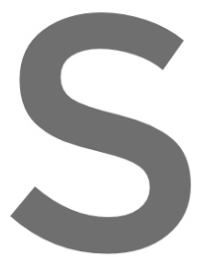

[1] Bus Terminal Aarau: Ingenieurbaukunst 2015, pages 70-79

[2] Bus Terminal Aarau: DBZ 12/2013, pages 28-35

[3] Bus station roof Hamburg-Barmbek: Stahlbaunachrichten 04/2013, pages 24-28
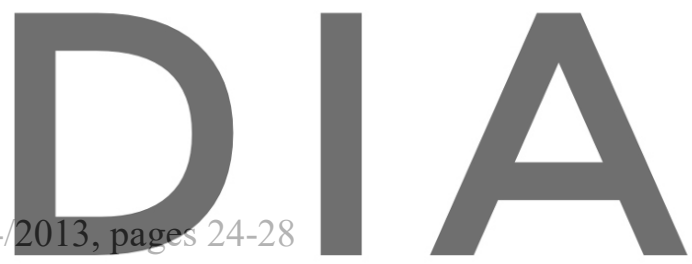

[4] https://www.eda.admin.ch/aboutswitzerland.html

Register for free at https//www.scipedia.com to download the version without the watermark 